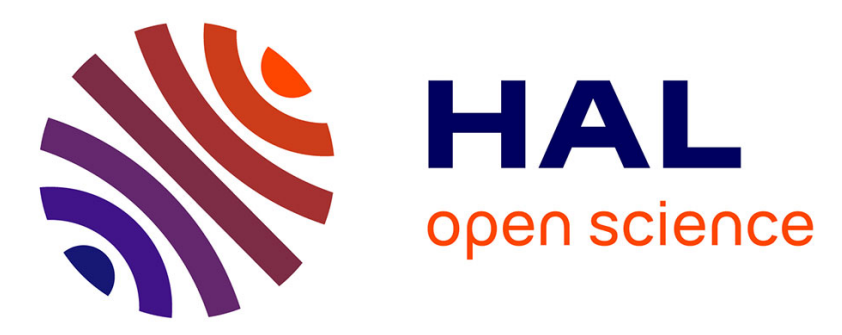

\title{
Evidence for an apical, nonregulated protein secretion in pig exocrine pancreas
}

\author{
G. Viau, J. Laine, Florence Levenez, A.M. Gueugneau, T. Corring, \\ Jean-Baptiste Morisset, D. Lebel
}

\section{- To cite this version:}

G. Viau, J. Laine, Florence Levenez, A.M. Gueugneau, T. Corring, et al.. Evidence for an apical, nonregulated protein secretion in pig exocrine pancreas. AJP - Gastrointestinal and Liver Physiology, 1994, 267, pp.G764-G771. hal-02711289

\section{HAL Id: hal-02711289 \\ https://hal.inrae.fr/hal-02711289}

Submitted on 1 Jun 2020

HAL is a multi-disciplinary open access archive for the deposit and dissemination of scientific research documents, whether they are published or not. The documents may come from teaching and research institutions in France or abroad, or from public or private research centers.
L'archive ouverte pluridisciplinaire $\mathbf{H A L}$, est destinée au dépôt et à la diffusion de documents scientifiques de niveau recherche, publiés ou non, émanant des établissements d'enseignement et de recherche français ou étrangers, des laboratoires publics ou privés. 


\title{
Evidence for an apical, nonregulated protein secretion in pig exocrine pancreas
}

\author{
GINETTE VIAU, JEAN LAINÉ, FLORENCE LEVENEZ, ANNE-MARIE GUEUGNEAU, \\ TRISTAN CORRING, JEAN MORISSET, AND DENIS LEBEL \\ Centre de Recherche sur les Mécanismes de Sécrétion, Université de Sherbrooke, Sherbrooke, Quebec \\ J1K 2R1, Canada; and Unité d'Écologie et de Physiologie du Système Digestif, Centre de Recherche \\ de l'Institut National de la Recherche Agronomique, F-78352 Jouy-en-Josas, France
}

\begin{abstract}
Viau, Ginette, Jean Lainé, Florence Levenez, AnneMarie Gueugneau, Tristan Corring, Jean Morisset, and Denis Lebel. Evidence for an apical, nonregulated protein secretion in pig exocrine pancreas. Am. J. Physiol. 267 (Gastrointest. Liver Physiol. 30): G764-G771, 1994.- Secretory proteins are segregated into two pathways out of the trans-Golgi network of regulated secretory cells. To identify proteins specifically secreted by pathways other than the one leading to zymogen granule exocytosis in the exocrine pancreas, conscious permanently cannulated pigs were perfused with atropine to inhibit the regulated fusion of granules. Atropine almost totally inhibited the protein secretion after $1 \mathrm{~h}$ of perfusion. The secretion of GP-2, a glycosyl phosphatidylinositol-anchored protein of the zymogen granule membrane, was partially inhibited but was never totally abolished by atropine perfusion. The pattern of proteins secreted under atropine was almost totally different. Soluble GP-2 was the major secretory product. Its specific activity increased 60 times over its normal level in all other conditions. This secretion clearly originated from nonregulated pathways. Results suggest that during the atropine block the apical plasmalemma could be the source of the released GP-2 and that the sustained nature of this release is compatible with a replenishment of the plasmalemma with GP-2 by the continuous exocytosis of vesicles from the nonregulated pathways.
\end{abstract}

resting; maturative; constitutive; polarity; cannulated pancreas; conscious animal

ALL CELLS have the capacity to continually secrete proteins by exocytosis at their surface using vesicles that originate from the Golgi complex. This universal mode of secretion is called the constitutive secretory pathway (7). Some cells possess an additional secretory pathway that accumulates specific secretory products in specialized organelles called secretory vesicles or granules. These storage granules fuse with the plasma membrane and release their content at the cell surface in an amplified manner exclusively in response to stimulation by external signals. This pathway is called the regulated secretory pathway (7). The pancreatic acinar cell is an example of a cell that possesses these two pathways, although regulated secretion is massively dominant in terms of secretory output and morphology of the cell. A third secretory pathway has been evidenced in cells of exocrine and endocrine origin possessing a regulated pathway $(2,12,18)$. This additional pathway, which we refer to as the maturative secretory pathway, is dependent on the existence of newly made secretory granules undergoing maturation (3).

In the exocrine pancreas the regulated secretory pathway is responsible for the primary function of the gland: the secretion of digestive enzymes. The natural and physiological stimulus that induces massive exocytosis of zymogen granules is the ingestion of food. It is effected by nervous (cholinergic) and hormonal mediators [cholecystokinin (CCK) and secretin] that find their specific receptors on the basolateral membrane of acinar cells. At the structural level, zymogen granules are the dominant features at the apical pole of pancreatic acinar cells. The regulated release of these granules has been extensively studied. The pancreatic acinar cell was indeed the first model used to define the regulated secretory pathway (29). On the other hand, the constitutive secretory pathway remains a more elusive phenomenon $(2,4)$. Its transport vesicles cannot be morphologically distinguished without use of clear markers (36). Particularly in the exocrine pancreas, the constitutive pathway has only been partially characterized (2). Due to the acinar cell polarity, two types of constitutive secretion exist: one at the basolateral pole, the other at the apex of the cell. In addition, to serve as transporters of membrane proteins and lipids for the biogenesis of the two specialized plasma membranes, the vesicles transporting the constitutive secretion must also have different protein contents corresponding to the specific function at each pole. Vesicles headed for the basolateral pole are believed to mainly secrete the building elements of the basement membrane, i.e., collagen, proteoglycans, etc. In contrast, the apical pole of the cell is totally dedicated to secretion related to digestion. Indeed, the sole destination of apical secretions is the lumen of the duodenum. Therefore it is difficult to envision proteins other than digestive proteins that could be constitutively secreted at the apical pole. As previously estimated by pulse-chase experiments $(2,4)$, pancreatic nonregulated secretion represents less than $15 \%$ of the newly synthesized proteins of the gland at rest, and most of these proteins were shown to be zymogens.

Studies at the cellular level of the two distinct polarized secretions of the exocrine pancreas are still hampered by the lack of well-differentiated cell lines that can grow in a fully polarized fashion, as kidney [MadinDarby canine kidney (MDCK)] and intestinal (Caco) cells do. A privileged model that allies the benefit of specifically collecting apical secretions in large amounts with the benefit of modulating this secretion in situ under ideal physiological conditions is the conscious cannulated pig (8). In this article we took advantage of this model to characterize the apical nonregulated secretion of the exocrine pancreas. The rationale of the study was to inhibit the basal release of secretagogues, which causes a background of regulated secretion in the living 
animal. Pig pancreas is relatively unresponsive to $\mathrm{CCK}$ (9). Moreover, at physiological concentrations, CCK has been shown to stimulate secretion via a cholinergic pathway (35). Conversely, pig pancreas is very sensitive to cholinergic stimulation (13). Atropine perfusion was therefore used to inhibit the basal level of regulated secretion in cannulated pigs. Here we report that atropine inhibited very effectively the basal secretion in the conscious pig. Under these conditions a virtual absence of regulated secretion was attained: extremely low amounts of proteins were secreted consisting of only six different polypeptides. The major protein was a soluble form of the zymogen granule membrane GP-2. These observations shed new light on the nonregulated pathways of secretion of the exocrine pancreas and their relative significance in the function of the gland.

\section{MATERIALS AND METHODS}

Experimental protocol. Large White hogs $(\sim 50 \mathrm{~kg}$, live weight) were fitted with two permanent cannulas under halothane anesthesia as previously described (8). One cannula was inserted into the pancreatic duct, while the other was positioned into the duodenum for restitution of the pancreatic juice. A Silastic catheter was positioned into the jugular vein for perfusion of secretagogues and atropine. After an overnight fast with free access to water, cannulated pigs were perfused at $10 \mathrm{ml} / \mathrm{h}$ with saline containing $0.5 \%$ porcine serum albumin (saline-PSA) for a period of $1 \mathrm{~h}$. Stimulation was then initiated by intravenous perfusion of secretin dissolved in saline-PSA at $36 \mathrm{pmol} \cdot \mathrm{kg}^{-1} \cdot \mathrm{h}^{-1}$ for $3 \mathrm{~h}$ and, when indicated, with secretin plus CCK $\left(600 \mathrm{pmol} \cdot \mathrm{kg}^{-1} \cdot \mathrm{h}^{-1}\right)$ in the same vehicle. In some experiments, atropine dissolved in saline-PSA was intravenously infused $2 \mathrm{~h}$ after the beginning of the secretin or sccretin plus CCK stimulation at doses of 10,25 , 50,100 , or $200 \mu \mathrm{g} \cdot \mathrm{kg}^{-1} \cdot \mathrm{h}^{-1}$. Secretions were continuously collected, retaining $25 \%$ of the volume that was pooled in 30 -min fractions. The catheters for pancreatic juice collection and return were connected to an apparatus that immediately reintroduced the secreted pancreatic juice into the duodenum (17) to maintain the feedback inhibition produced by the continuous flow of pancreatic secretions in the intestine.

Analytical methods. The volume and the concentration of protein and of GP-2 were monitored for every sample. Protein was determined by the Bradford procedure (6). In Figs. 1 and 2, GP-2 was assayed using a competitive enzyme-linked immunoabsorbent assay specific for the pig GP-2 that was developed in our laboratory as an adaptation of a procedure previously described for the rat GP-2 (26). Amylase, lipase, trypsin, chymotrypsin, and elastase activities were kinetically assayed in microplates using previously described procedures (20). Sodium dodecyl sulfate-polyacrylamide gel electrophoresis (SDS-PAGE) was performed using the discontinuous buffer system of Laemmli (19) (12\% gels). Samples for SDS-PAGE were concentrated by freeze-drying when necessary, reduced with $1 \% \beta$-mercaptoethanol, and heated at $90^{\circ} \mathrm{C}$ for $3 \mathrm{~min}$. Electrophoresis reagents were from Bio-Rad. Immunoblotting was carried out using standard procedures (31) with specific anti-pig GP-2 and anti-inositol 1,2-cyclic monophosphate (from Dr. N. M. Hooper, Univ. of Leeds, UK). Phase separation using Triton X-114 of soluble and membrane-bound proteins was performed according to previously published procedures (1, 31). All chemicals were of analytical grade.
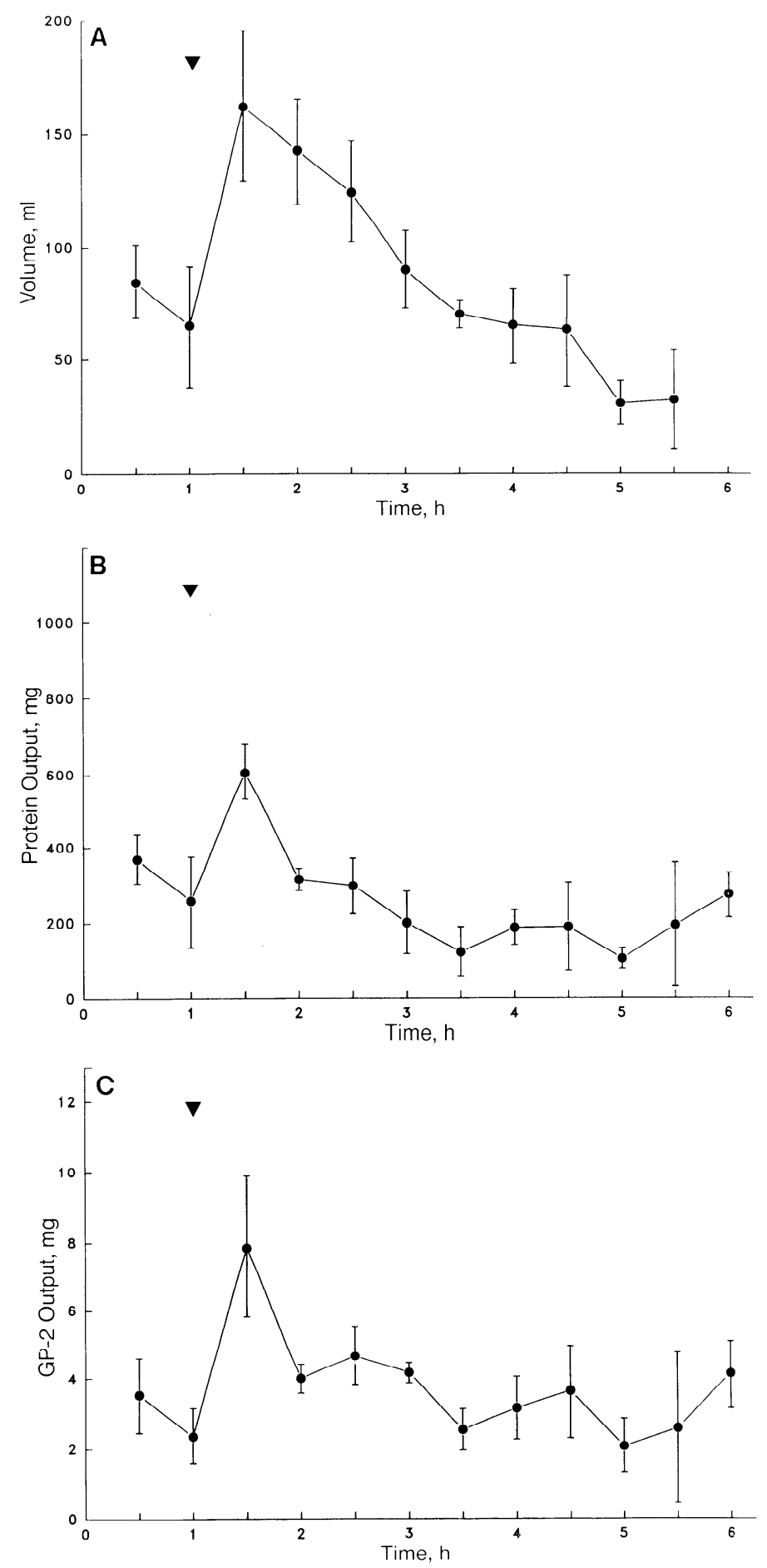

Fig. 1. Secretory response of pig cannulated pancreas to secretin stimulation. Cannulated conscious pigs with permanent pancreatic cannulas were intravenously perfused with $36 \mathrm{pmol} \cdot \mathrm{kg}^{-1} \cdot \mathrm{h}^{-1}$ of secretin starting at $1 \mathrm{~h}$ (arrowhead) and ending at $4 \mathrm{~h}$. Saline porcine serum albumin (saline-PSA) was perfused for $1 \mathrm{~h}$ before hormone perfusion. Pancreatic secretion was sampled into 30 -min aliquots. Secretion was monitored for volume $(A)$, protein $(B)$, and total GP-2 output $(C)$. Each point represents mean $\pm \mathrm{SE}$ of 3 experiments.

\section{RESULTS}

Secretory response to secretin. To have a minimum volume of secretion to work with under inhibitory conditions, secretin was infused during all experiments. 

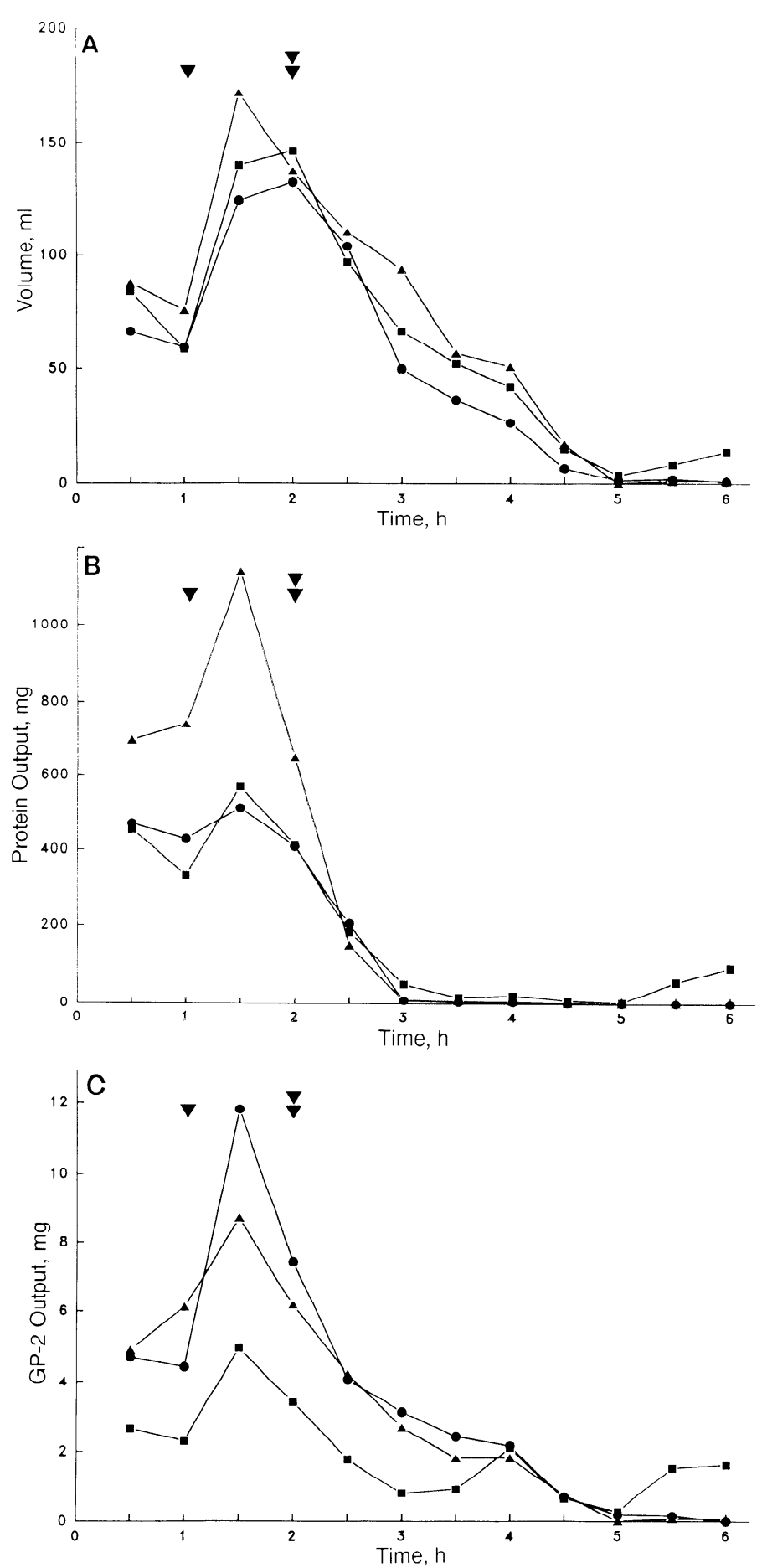

Fig. 2. Inhibition of secretory responsc of pig cannulated pancreas by atropine under secretin perfusion. Cannulated conscious pigs with permanent pancreatic cannulas were intravenously perfused with 36 $\mathrm{pmol} \cdot \mathrm{kg}^{-1} \cdot \mathrm{h}^{-1}$ of secretin starting at $1 \mathrm{~h}$ (arrowhead) and ending at 4 $\mathrm{h}$ as described in Fig. 1. Cannulated secretion was pooled in $30-\mathrm{min}$ fractions. Atropine was perfused starting at $2 \mathrm{~h}$ (double arrowhead) and lasted $2 \mathrm{~h}$. Three doses of atropine were used: $10(\square), 50(\bullet)$, and $200(\Lambda) \mu \mathrm{g} \cdot \mathrm{kg}^{-1} \cdot \mathrm{h}^{-1}$. Secretion was monitored for volume $(A)$, protein $(B)$, and total GP-2 output $(C)$. Each curve represents a separate experiment. In $A$, the curve is the mean of either $5(10-\mu \mathrm{g}$ dose), 3

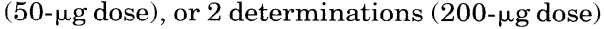

Secretin has been chosen because this secretagogue is known to exclusively induce secretion of water and bicarbonates in the conscious cannulated pig at the employed concentrations (21). The dose infused is the one that gives a circulating level of secretin equivalent to that induced by the ingestion of a meal (22). Fig. $1 \mathrm{~A}$ shows the effect of secretin on the volume of the pancreatic cannulated secretion during a $3-\mathrm{h}$ perfusion. The volume doubled after the first $0.5 \mathrm{~h}$ of perfusion, to decrease slowly to basal level after $2 \mathrm{~h}$ of perfusion. Under the same conditions, protein secretion did not increase significantly (Fig. $1 B$ ) except for a slight increase in output observed at $1.5 \mathrm{~h}$ that would represent a washout of pancreatic ducts generated by the increased flow of water. As for the secretion of GP-2, a slight peak concomitant with that of proteins was also observed after $0.5 \mathrm{~h}$ of secretin perfusion (Fig. $1 C$ ). This peak constituted a twofold increment over the amount secreted under basal conditions. This higher level of GP-2 was transient because basal level was already reinstated in the following $30 \mathrm{~min}$, which also is consistent with washout of the pancreatic ducts. Thus in our experimental conditions stimulation of the regulated pathway by secretin was, at most, modest.

Inhibitory effects of atropine under secretin perfusion. Atropine perfusions were carried out under secretin perfusion as shown above. Three doses of atropine were used: 10,50 , and $200 \mu \mathrm{g} \cdot \mathrm{kg}^{-1} \cdot \mathrm{h}^{-1}$. As shown in Fig. 2, only small effects on volumes were detected (compare Fig. $2 A$ and Fig. 1A). In contrast, inhibition of protein secretion was almost total after only $1 \mathrm{~h}$ of atropine perfusion (Fig. $2 B$ ), down from $\sim 500 \mathrm{mg} / 30 \mathrm{~min}$ to less than $3 \mathrm{mg} / 30 \mathrm{~min}$. A parallel decrease was observed for amylase, lipase, trypsin, chymotrypsin, and elastase (results not shown). On the other hand, the level of GP-2 steadily decreased (Fig. $2 C$ ) from $\sim 4.8 \mathrm{mg} / 30 \mathrm{~min}$ down to $\sim 0.5 \mathrm{mg} / 30 \mathrm{~min}$ after $3 \mathrm{~h}$ of inhibition, a decrease of more than $90 \%$. However, in the first $2 \mathrm{~h}$ of atropine perfusion the decrease of GP-2 was less than $50 \%$, quite modest compared with the inhibition of the protein output. No dose-dependent effect of atropine was noticed. Inhibition of protein secretion was already maximal at $\sim 10 \mu \mathrm{g} \cdot \mathrm{kg}^{-1} \cdot \mathrm{h}^{-1}$ of atropine. Basal levels of secretion varied from one day to another, and between pigs. These experiments clearly show that regulated secretion was drastically inhibited by atropine, since a decrease in protein secretion is the most direct and reliable indication of an inhibition of the acinar cellregulated secretory pathway. Therefore, atropine addition to secretin-perfused, fasted, cannulated pigs was a reliable model to maximally inhibit regulated secretion originating from pancreatic acinar cells.

Effect of atropine on the protein composition of pancreatic secretions. Polyacrylamide gel electrophoresis of the secretions before and after atropine perfusion is shown in Fig. 3. The first observation is that the pattern of proteins was dramatically altered by atropine perfusion. A protein of 92,000 Da that cannot be seen under secretin perfusion became one of the major components in the first hour after atropine addition. A protein with the same mobility as amylase [apparent molecular mass 


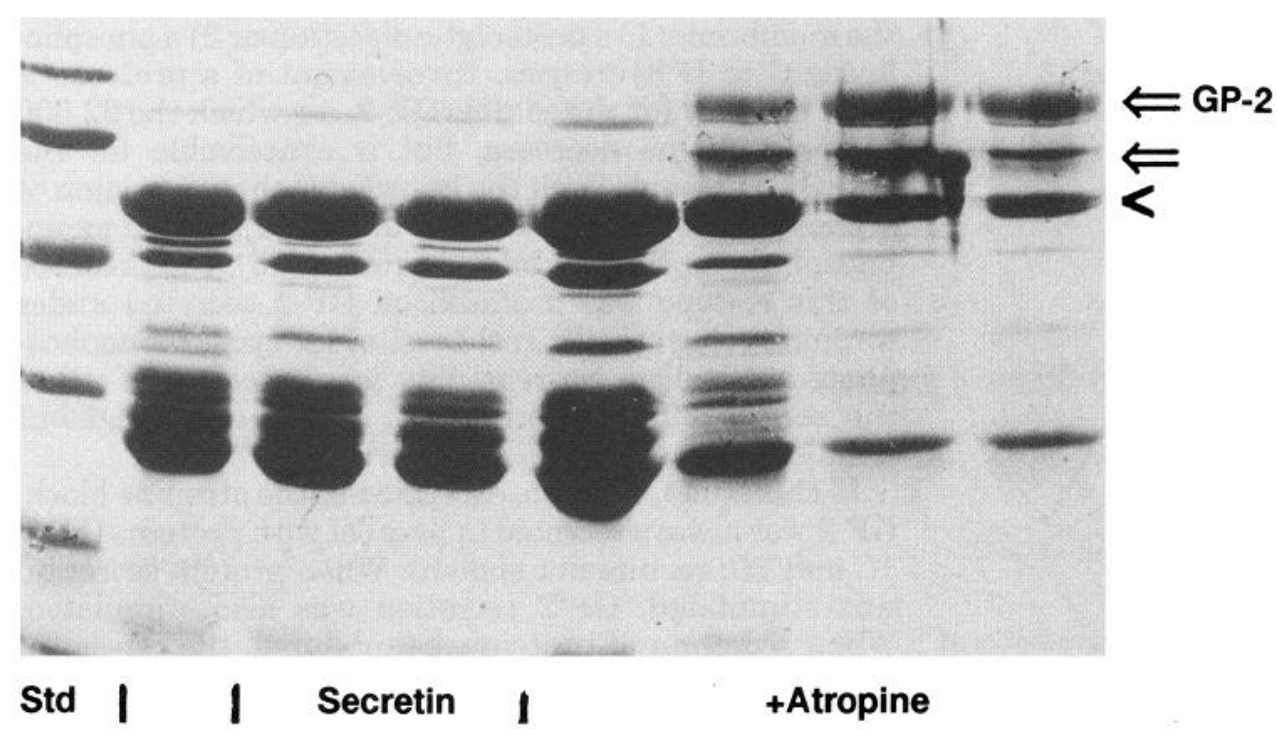

Fig. 3. Effect of atropine on protein composition of cannulated pig pancreatic secretions. SDS-polyacrylamide gel electrophoresis (SDS-PAGE) of cannulated pancreatic secretions (Fig. 2) was inhibited by perfusion of $50 \mu \mathrm{g} \cdot \mathrm{kg}^{-1} \cdot \mathrm{h}^{-1}$ of atropine under secretin perfusion ( 36 $\left.\mathrm{pmol} \cdot \mathrm{kg}^{-1} \cdot \mathrm{h}^{-1}\right)$. Effort was made to put the same amount of protein $(\sim 20 \mu \mathrm{g})$ in each lane to identify protein composition of secretions. Secretin samples were done at 1.5 and $2 \mathrm{~h}$. Atropine samples were done at $2.5,3,3.5$, and $4 \mathrm{~h}$. First sample at left was under saline perfusion. Intact GP-2 and a proteolytic fragment identified by immunoblotting (see Fig. 4) are indicated by arrows. The 55,000-Da band (arrowhead) was identified as amylase by immunodetection (results not shown). $M_{\mathrm{r}}$ values of standards at left are $94,000,66,000,46,000,30,000$, 21,000 , and $14,000 \mathrm{Da}$ (top to bottom).
$\left.\left(M_{\mathrm{r}}\right) \sim 55,000\right]$ is the other major constituent of this atropine-inhibited secretion. Its identity with amylase was confirmed by probing the blot with anti-amylase antibodies (results not shown). Since the $92-\mathrm{kDa}$ band was likely to be GP-2, an immunoblot was carried out with anti-GP-2 antibodies. Figure 4, top, shows that the $92-\mathrm{kDa}$ band is the intact GP-2 (23) and that the lower band at $\sim 65 \mathrm{kDa}$ is a GP-2 fragment (Fig. 4, bottom). The latter corresponds to the GP-2 fragment previously

\section{GP-2 immunoblot}

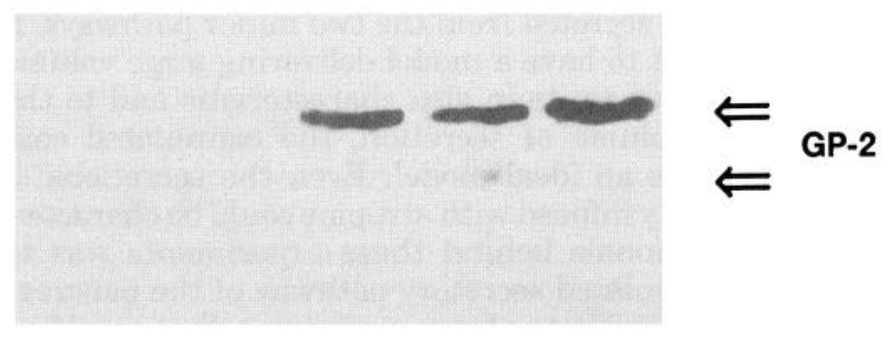

Secretin $\quad$ +Atropine

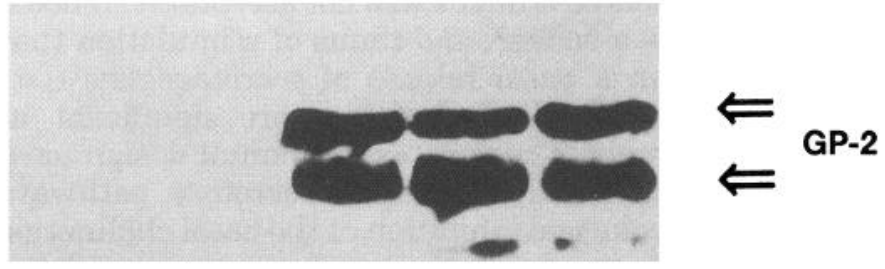

Fig. 4. Immunocharacterization of GP-2 secreted under atropine perfusion. Top: immunoblot was performed with 5 right lanes of an SDS-PAGE made of samples produced under conditions of atropine perfusion similar to the gel in Fig. 3 using specific anti-pig GP-2 antibodies. Secretin sample was at $2 \mathrm{~h}$, and atropine samples were at $2.5,3,3.5$, and $4 \mathrm{~h}$. GP-2 is immunodetected after $1 \mathrm{~h}$ of atropine block. Bottom: same immunoblot was overexposed to see minor bands. Two immunoreactive bands were revealed at $92,000 \mathrm{Da}$ for intact GP-2 and at $\sim 65,000 \mathrm{Da}$ for a fragment. Although GP-2 release from basal exocytosis of secretory granules is largely in parallel with zymogen discharge, GP-2 was not visible in the 2 left lanes in this experiment, indicating that such secretion was below detection by immunoblotting. evidenced in pig zymogen granule membranes (30) and secretions (25).

As seen in Figs. 3 and 4, GP-2 was the major component of atropine-blocked secretions. To estimate the relative proportion of GP-2 in these secretions, we calculated the specific activity of GP-2 expressed in micrograms of GP-2 per milligram of protein. Specific activity typically varied from 5 to $20 \mu \mathrm{g}$ GP- $2 / \mathrm{mg}$ protein at all times in absence of atropine. Actually Fig. 3 is a visual estimation of this increase in the specific activity of GP-2 induced by the atropine block. Under strong inhibition by atropine the specific activity increased dramatically to reach $600 \mu \mathrm{g}$ GP-2/mg protein (Fig. 5), an increase of up to 60 times the basal value. This phenomenon was also observed even when CCK $\left(600 \mathrm{pmol} \cdot \mathrm{kg}^{-1} \cdot \mathrm{h}^{-1}\right)$ was added to secretin in the background perfusion (Fig. 5). Under continuous secretin perfusion the specific activity of GP-2 remained constant, proving that the increase in specific activity was a direct effect of the atropine perfusion. Specific activities of amylase, lipase, trypsin, chymotrypsin, or elastase were not affected by this atropine perfusion (results not shown).

Characterization of GP-2 secreted under atropine perfusion. During its intracellular transit, GP-2 is initially bound to a glycosyl phosphatidylinositol anchor in the endoplasmic reticulum and stays in this form up to the trans-Golgi (11) and the zymogen granule membrane (24). In addition, about one-half of the GP-2 is in a soluble form in the zymogen granule content (30). To assess the soluble or membranous nature of the GP-2 secreted during the atropine block, phase separation in Triton X-114 solutions was performed. In this system, hydrophobic membrane-bound proteins like membranous GP-2 (24) selectively partition in the detergent phase, whereas soluble proteins go to the aqueous phase. As shown in Fig. 6, the secreted GP-2 partitioned entirely into the aqueous phase, showing that the glycoprotein had lost its lipid membrane anchor. Two biochemical processes could have released GP-2 from 


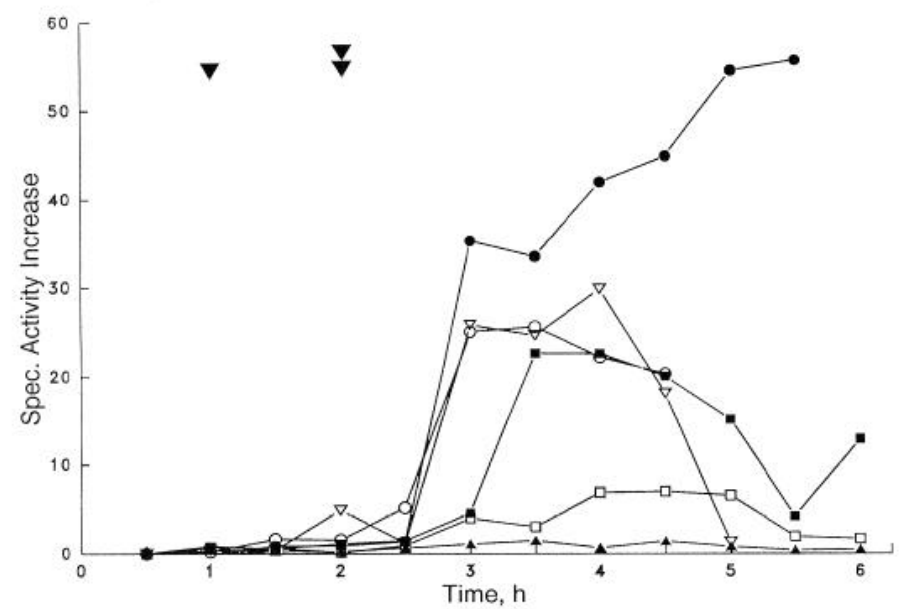

Fig. 5. Effect of atropine on specific activities of GP-2 in cannulated secretion of pig pancreas. Cannulated conscious pigs with permanent pancreatic cannulas were intravenously perfused with 36 $\mathrm{pmol} \cdot \mathrm{kg}^{-1} \cdot \mathrm{h}^{-1}$ of secretin (filled symbols) or with secretin plus CCK (open symbols) at $600 \mathrm{pmol} \cdot \mathrm{kg}^{-1} \cdot \mathrm{h}^{-1}$ starting at $1 \mathrm{~h}$ (arrowhead) and ending at $4 \mathrm{~h}$ as described in Fig. 1. Three doses of atropine were used: $10(\square, \square), 25(\nabla)$, and $50(\bullet, \circ) \mu \mathrm{g} \cdot \mathrm{kg}^{-1} \cdot \mathrm{h}^{-1}$. Atropine perfusion started at $2 \mathrm{~h}$ (double arrowhead) and lasted $2 \mathrm{~h}$. Secretion was monitored for protein and total GP-2 output (see Fig. 2 for results) and expressed as fold of increase in GP-2 specific activity, taking specific activity ( $\mu \mathrm{g}$ of GP-2/mg of protein) at $0.5 \mathrm{~h}$ as the basal reference of no increase. Specific activities of GP-2 at $0.5 \mathrm{~h}$ were $5.26(\mathbf{\square}), 26.07(\square)$, $30.18(\nabla), 10.56(\bullet)$, and $14.04(\bigcirc) \mu \mathrm{g} \mathrm{GP}-2 / \mathrm{mg}$ protein. As a control, the lack of change in specific activity of GP-2 under secretin perfusion without atropine is shown ( $\mathbf{\Lambda}$ ). Each curve represents a separate experiment.

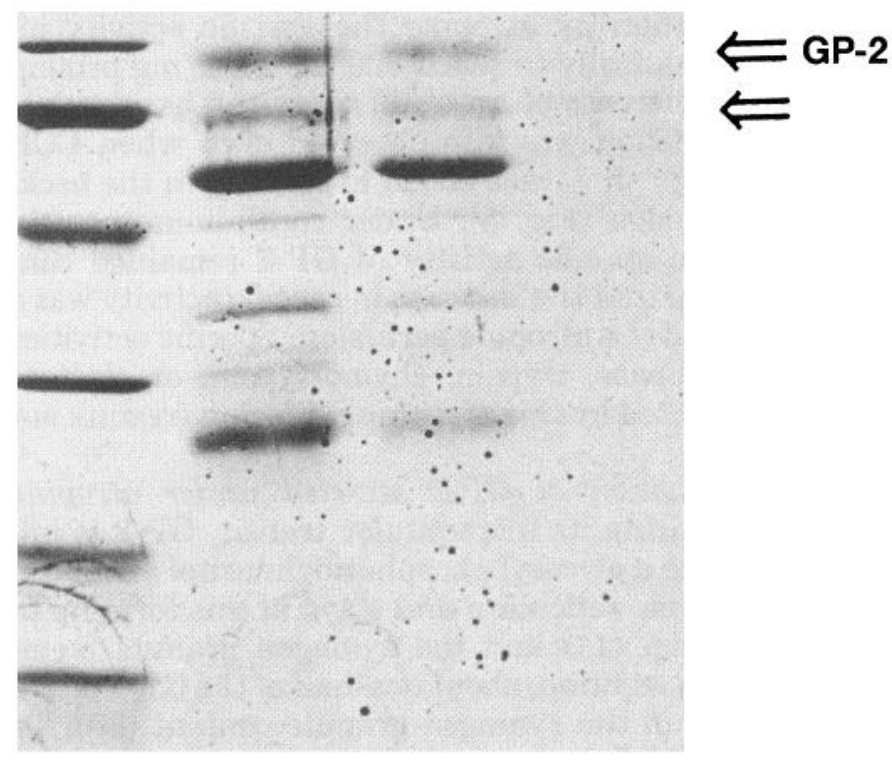

\section{Std Tot Aq Det}

Fig. 6. Triton X-114 phase separation of proteins secreted under atropine perfusion. Triton X-114 phase separation was performed with proteins secreted under atropine perfusion. Membrane-bound proteins partition in the detergent phase (Det), and soluble proteins partition in the aqueous phase (Aq). All GP-2 secreted under atropine (Fig. 3) was quantitatively recovered in the aqueous phase. Arrows show intact GP-2 and its proteolytic fragment. SDS-PAGE was stained with Coomassie blue; left track shows $M_{\mathrm{r}}$ standards of $94,000,66,000$, $46,000,30,000,21,000$, and $14,000 \mathrm{Da}$ (top to bottom). the membrane: 1) a proteolytic digestion or 2) a phospholipase C or D hydrolysis. Involvement of a protease is most unlikely for the soluble GP-2, for which the 92,000 $M_{\mathrm{r}}$ presents no decrease, but is conceivable for the $65-\mathrm{kDa}$ fragment. With the knowledge that the action of a phospholipase C exposes an inositol 1,2-cyclic monophosphate on the solubilized protein (15), the presence of this epitope was assessed on GP-2 secreted under atropine using specific anti-inositol 1,2-cyclic monophosphate antibodies. No reactivity was detected on either the secreted $92-\mathrm{kDa}$ protein or the $65-\mathrm{kDa}$ fragment (results not shown).

In this study, with the exception of the atropine block, GP-2 was always secreted in parallel with proteins (Figs. $1 C$ and $2 C$; results not shown). When protein secretion was stimulated, GP-2 secretion was also stimulated. When secretion of protein was inhibited, the release of GP-2 also decreased. As mentioned previously, excluding the atropine block, the specific activity of GP-2 was comparable in all conditions at all times reported. This secretory behavior has been observed before $(32,34)$ and was expected in the cannulated pig, since about $50 \%$ of the GP-2 is soluble in the granule content (30). In other words, GP-2 can be considered as a bona fide regulated secretory protein in most physiological conditions.

\section{DISCUSSION}

The aim of this study was to attempt characterization of the constitutive and maturative secretory pathways in the exocrine pancreas. These two pathways are secondary to the principal route of secretion, the regulated secretory pathway. Since very little protein was expected to be secreted from the two minor pathways, it was important to have a model delivering large volume of samples. Due to its in situ characteristic and to the substantial volume of secretion, the cannulated conscious pig was an ideal model. Even the secretions of animals acutely infused with atropine could be characterized. The rationale behind these experiments was to inhibit the regulated secretory pathway of the pancreas as much as possible to obtain a secretion that would be enriched in constituents from the other secretory pathways. In this regard, straight collection of secretions from nonstimulated animals was not acceptable. Indeed, there is always a background tonus of stimulation that originates from a basal release of secretagogues (i.e., CCK and acetylcholine) that is more significant in conscious animals. Thus the experimental design used to characterize these alternative secretory pathways was a pharmacological inhibition of the basal cholinergic stimulation by atropine perfusion. In the pig, regulated secretion is known to be very heavily dependent on cholinergic stimulation (14) and much less dependent on hormonal (CCK) stimulation (9). This was confirmed by our observations showing that the basal unstimulated secretion in the conscious pig was abolished by the cholinergic muscarinic antagonist atropine. To have a volume of secretion large enough to measure the secretory products, secretin was infused to increase the output of volume, but with the lowest possible stimulation of protein secretion. With the exception of an 
increase in protein secretion due to an immediate and limited washout of secretory products already present in the pancreatic ducts before the perfusion (Fig. $1 B$ ), the response to secretin was mainly water (Fig. $1 A$ ). This conclusion was further confirmed by the effect of atropine on the two parameters that were monitored: the output of proteins was drastically inhibited (Fig. $2 B$ ), whereas that of the volume was less strongly affected (Fig. $2 A$ ). Atropine reduced protein output from $\sim 600$ $\mathrm{mg} / 30 \mathrm{~min}$ before perfusion (time $1.5 \mathrm{~h}$ ) to less than 6 $\mathrm{mg} / 30 \mathrm{~min}$ (at time $3.5 \mathrm{~h}$ and later) (Fig. $2 B$ ). These observations suggest that regulated secretion, which is a direct manifestation of the exocytosis of zymogen granules, has been almost eliminated by atropine in these cannulated pigs. However, GP-2 output decreased in a much less significant manner, showing that a meaningful source of GP-2 in resting secretions is not due to the regulated pathway. At these levels of secretion one can presume that constitutive and maturative pathways have a major contribution and can thus be characterized. In fact, the pattern of proteins secreted under the atropine block was radically different, which is a clear confirmation of the diminution of the regulated pathway and of the emergence of alternative pathways of secretion. During the atropine block, GP-2 and its proteolytic fragment (Figs. 3 and 4) were the major components of these secretions. Can the dramatic change in the composition of secretions produced by atropine be interpreted in terms of secretory vesicles responsible for delivering these proteins to the apical pole of the pancreatic acinar cell? Could one of the three described secretory pathways evidenced in the exocrine pancreas carry this GP-2-rich secretion? Definitely not the regulated pathway. Two reasons justify this interpretation. First, most of the protein output was inhibited by atropine, proving that this secretion is the result of a cholinergic stimulus, thus corresponding unquestionably to the definition of a regulated secretion. Second, the pattern of proteins secreted before the atropine block is identical to the zymogen granule content, in contrast to the atropine perfusion, which shows a totally different protein pattern. The secretion under atropine block must then originate from pathways different from the regulated pathway.

Three possibilities can be considered to explain the origin of the GP-2-rich secretion during the atropine block: 1) release of GP-2 from the apical plasmalemma, 2 ) the constitutive pathway, and 3 ) the maturative pathway.

The first possibility is through release from the apical surface of the acinar cell. Whatever its origin, the final destination of membrane-bound GP-2 is the acinar cell apical membrane, where it has been positively localized (11). From there, a phospholipase C or D could release the glycosyl phosphatidylinositol-anchored protein in pancreatic secretions. But could the GP-2 resident of the apical membrane be accountable for the steady level of secretion during the $1.5 \mathrm{~h}$ of atropine perfusion? It could indeed be sufficient, since there is an important concentration of GP-2 at the cell apical surface (32). However, the latter process would be facilitated by a steady delivery of GP-2 at the apical membrane by the fusion of vesicles with GP-2 on their membranes. The presence of amylase and other unidentified zymogens in the secretions of atropine-blocked animals supports the existence of such a basal level of exocytosis that should originate from nonregulated pathways.

The second possibility, that the constitutive pathway could produce a secretion rich in GP-2, implies that GP-2, by free diffusion in the trans-Golgi network (TGN) membrane, would end up in vesicles that generate the constitutive pathway $(28,37)$ and, in this vesicle or at the cell surface, GP-2 would be released from the membrane. This pathway was evidenced by Havinga et al. (13) in dispersed rat acinar cells where GP-2 bypassed the mature zymogen granule to reach the cell surface, where it had a high turnover rate (13). However, due to the incapacity of this pathway to concentrate its cargo, we believe that it is less likely that this pathway could deliver high amounts of concentrated GP-2 to the cell apex.

By contrast to the constitutive pathway, it is known that GP-2 is massively drawn into the regulated pathway. GP-2 indeed coaggregates with pancreatic zymogens under mild acidic conditions similar to those prevailing in the TGN $(16,27)$. GP-2 also strongly self-associates at acidic $\mathrm{pH}(10)$ and is secreted as an insoluble matrix in the pancreatic duct $(32,33)$. This evidence suggests that the acidic conditions of the TGN responsible for sorting regulated proteins also contribute to interactions of GP-2 with the zymogens and with GP-2 itself. These acid-dependent interactions have a major consequence, that is, to drain GP-2 in the regulated secretory pathway. Therefore the high specific activity of GP-2 in secretions under the atropine block makes us believe that this secretion could be the result of a positive segregation into the regulated pathway and could originate from a compartment located downstream from the site where sorting takes place (TGN) but upstream from mature zymogen granules. A diversion of the regulated pathway, called the maturative pathway (3), has been described in the exocrine pancreas (2). It has been undoubtedly substantiated in pancreatic endocrine $\beta$-cells $(5,18)$ and in PC12 cells (12). We believe that this diversion of the regulated pathway is a possible source of GP-2 to the cell apical plasmalemma. The membrane of this vesicle could possibly replenish the apical membrane with GP-2 and allow, during the atropine block, a sustained level of release of GP-2 from the membrane and its ensuing secretion.

It was not possible to determine either the exact location of the release of GP-2 or the mechanism of release from the membrane. GP-2 could indeed be released in vesicles that carry it to the surface or at the apical membrane itself. The absence of inositol 1,2-cyclic monophosphate on the secreted GP-2 and the fact that the polypeptide was not apparently touched by proteases lead to more than one simple interpretation for the mechanism of release. Possibilities are as follows: 1) the action of a phospholipase $\mathrm{C}$ followed by the decyclization or hydrolysis of the phosphate on inositol, 2) the action of a phospholipase D, or, finally and least likely, 3) a 
proteolysis that would selectively release the $\mathrm{COOH}$ terminal glycan from the protein.

In conclusion, our results show that in addition to GP-2 secreted via the regulated exocytosis of secretory granules, some GP-2 is also released in a soluble form by a mechanism that is independent of the regulated secretory pathway. This secretion is possibly by the release of the resident GP-2 on the cell surface, but we believe that its sustained discharge under atropine block along with some zymogens is compatible with a continuous delivery to the cell surface by the maturative secretory pathway. It is, however, premature here to assign a unique pathway accountable for GP-2 secretion during the atropine block. These results also suggest that, in the pig, the total contribution of the maturative and the constitutive pathways to basal secretions at the apical pole of the acinar cell under normal physiological conditions is very limited in terms of protein output.

We thank Dr. Michel R. Pâquet for reading the manuscript and for helpful comments. We also thank Marlyne Beattie for providing excellent technical assistance.

This work was supported by grants to D. LeBel from National Sciences and Engineering Research Council (Canada), Fonds pour la Formation de Chercheurs et l'Aide à la Recherche (Québec), and the Canadian Cystic Fibrosis Foundation. Travel grants were provided by a Québec-France Cooperation project.

This is the 18th paper in the series, "Elucidation of the Mechanisms of Cellular Secretion."

Address for reprint requests: D. LeBel, Dept. of Biology, Univ. of Sherbrooke, Sherbrooke, Quebec J1K 2R1, Canada.

Received 28 May 1993; accepted in final form 20 May 1994

\section{REFERENCES}

1. Alcaraz, G., J. P. Kinet, N. Kumar, S. A. Wank, and H. Metzger. Phase separation of the receptor for immunoglobulin E and its subunits in Triton X-114. J. Biol. Chem. 259: 14922-14927, 1984.

2. Arvan, P., and J. D. Castle. Phasic release of newly synthesized secretory proteins in the unstimulated rat exocrine pancreas. $J$. Cell Biol. 104: 243-252, 1987.

3. Arvan, P., and J. D. Castle. Protein sorting and secretion granule formation in regulated secretory cells. Trends Cell Biol. 2: 327-331, 1992.

4. Arvan, P., and A. Chang. Constitutive protein secretion from the exocrine pancreas of fetal rats. J. Biol. Chem. 262: 3886$3890,1987$.

5. Arvan, P., R. Kuliawat, D. Prabakaran, A. M. Zavacki, D. Elahi, S. Wang, and D. Pilkey. Protein discharge from immature secretory granules displays both regulated and constitutive characteristics. J. Biol. Chem. 266: 14171-14174, 1991.

6. Bradford, M. M. A rapid and sensitive method for the quantitation of microgram quantities of protein utilizing the principle of protein-dye binding. Anal. Biochem. 72: 248-254, 1976.

7. Burgess, T. L., and R. B. Kelly. Constitutive and regulated secretion of proteins. Annu. Rev. Cell Biol. 3: 243-293, 1987.

8. Corring, T., A. Aumaitre, and A. Rerat. Fistulation permanente du pancréas exocrine chez le porc. Application: réponse de la sécrétion pancréatique au repas. Ann. Biol. Anim. Biochim. Biophys. 12: 109-124, 1972.

9. Cuber, J. C., T. Corring, F. Levenez, C. Bernard, and J.-A. Chayvialle. Effects of cholecystokinin octapeptide on the pancreatic exocrine secretion in the pig. Can. J. Physiol. Pharmacol. 67: 1391-1397, 1989.

10. Fukuoka, S. I., S. D. Freedman, H. Yu, V. P. Sukhatme, and G. A. Scheele. GP-2/THP gene family encodes self-binding glycosyl phosphatidylinositol-anchored proteins in apical secretory compartments of pancreas and kidney. Proc. Natl. Acad. Sci. USA 89: 1189-1193, 1992.
11. Geuze, H. J., J. W. Slot, P. A. van der Ley, and R. C. T. Scheffer. Use of colloidal gold particles in double-labeling immunoelectron microscopy of ultrathin frozen tissue sections. J. Cell Biol. 89: 653-665, 1981

12. Grimes, M., and R. B. Kelly. Intermediates in the constitutive and regulated secretory pathways released in vitro from semiintact cells. J. Cell Biol. 117: 539-549, 1992.

13. Havinga, J. R., G. J. Strous, and C. Poort. Intracellular transport of the major glycoprotein of zymogen granule membranes in the rat pancreas. Demonstration of high turnover at the plasma membranc. Eur. J. Biochem. 144: 177-183, 1984.

14. Holst, J. J., O. B. Schaffalitzky de Muckadell, and J. Fahrenkrug. Nervous control of pancreatic exocrine secretion in pigs. Acta Physiol. Scand. 105: 33-51, 1979.

15. Hooper, N. M., S. J. Broomfield, and A. J. Turner. Characterization of antibodies to the glycosyl-phosphatidylinositol membrane anchors of mammalian proteins. Biochem. J. 273: 301-306, 1991.

16. Jacob, M., J. Lainé, and D. LeBel. Specific interactions of pancreatic amylase at acidic $\mathrm{pH}$. Amylase and the major protein of the zymogen granule membrane (GP-2) bind to purified amylase when immobilized or polymerized. Biochem. Cell Biol. 70: 1105$1114,1992$.

17. Juste, C., T. Corring, and Y. Le Coz. Bile restitution procedure for studying bile secretion in fistulated pigs. Lab. Anim. Sci. 33: 99-102, 1983.

18. Kuliawat, R., and P. Arvan. Protein targeting via the "constitutive-like" secretory pathway in isolated pancreatic islets: passive sorting in the immature granule compartment. J. Cell Biol. 118: 521-529, 1992

19. Laemmli, U. K. Cleavage of structural proteins during the assembly of the head of bacteriophage T4. Nature Lond. 227: 680-685, 1970.

20. Lainé, J., M. Beattie, and D. LeBel. Simultaneous kinetic determination of lipase, chymotrypsin, trypsin, elastase and amylase on the same microtiter plate. Pancreas 8: 383-386, 1993.

21. Langlois, A. Contribution à l'Étude de la Régulation Hormonale des Sécrétions Digestives Chez le Porc (PhD thesis). Paris: Univ. de Paris VII, 1989.

22. Langlois, A., T. Corring, J.-C. Cuber, A.-M. Gueugneau, F. Levenez, and J.-A. Chayvialle. Effects of pancreatic polypeplide on the pancreatic exocrine secretion stimulated by secretin and cholecystokinin in the conscious pig. Regul. Pept. 24: 55-65, 1989.

23. LeBel, D., and M. Beattie. The integral and peripheral proteins of the zymogen granule membrane. Biochim. Biophys. Acta 769: 611-621, 1984.

24. LeBel, D., and M. Beattie. The major protein of pancreatic zymogen granule membranes (GP-2) is anchored via covalent bonds to phosphatidylinositol. Biochem. Biophys. Res. Commun. 154: 818-823, 1988.

25. LeBel, D., and A. R. Beaudoin. Different patterns of proteins are secreted by the pig pancreas when stimulated by secretin alone or in combination with caerulein. Biochim. Biophys. Acta 847: $132-135,1985$.

26. Leblond, F. A., B. G. Talbot, I. Lauzon, and D. LeBel. A competition enzyme-linked immunosorbent assay (ELISA) for the measurement of pancreatic GP-2 glycoprotein. J. Immunol. Methods 124: 71-75, 1989.

27. Leblond, F. A., G. Viau, and D. LeBel. Reconstitution in vitro of the $\mathrm{pH}$-dependent aggregation of pancreatic zymogens en route to the secretory granule: implication of GP-2. Biochem. J. 291: 289-296, 1993.

28. Noda, M., K. Yoon, G. A. Rodan, and K. E. Koppel. High lateral mobility of endogenous and transfected alkaline phosphatase: a phosphatidylinositol-anchored membrane protein. J. Cell Biol. 105: 1671-1677, 1987.

29. Palade, G. Intracellular aspects of the process of protein synthesis. Science Wash. DC 189: 347-358, 1975.

30. Paquette, J., F. A. Leblond, M. Beattie, and D. LeBel. Reducing conditions induce a total degradation of the major 
zymogen granule membrane protein in both its membranous and its soluble form. Immunochemical quantitation of the two forms. Biochem. Cell Biol. 64: 456-462, 1986.

31. Paul, E., F. A. Leblond, and D. LeBel. In resting conditions, the pancreatic granule membrane protein GP-2 is secreted by cleavage of its glycosylphosphatidylinositol anchor. Biochem. J. 277: 879-881, 1991.

32. Rindler, M. J., and T. C. Hoops. The pancreatic membrane protein GP-2 localizes specifically to secretory granules and is shed into the pancreatic juice as a protein aggregate. Eur. J. Cell Biol. 53: 154-163, 1990.

33. Scheele, G. A., S. I. Fukuoka, and S. D. Freedman. Role of GP-2/THP family of GPI-anchored proteins in membrane trafficking during regulated exocrine secretion. Pancreas 9: 139-149, 1994.

34. Scheffer, R. C. T., C. Poort, and J. W. Slot. Fate of the major zymogen granule membrane-associated glycoproteins from rat pancreas. A biochemical and immunocytochemical study. Eur. eJ. Cell Biol. 23: 122-128, 1980.

35. Soudah, H. C., Y. Iu, W. L. Hasler, and C. Owyang. Cholecystokinin at physiological levels evokes pancreatic enzyme secretion via a cholinergic pathway. Am. J. Physiol. 263 (Gastrointest. Liver Physiol. 26): G102-G107, 1992.

36. Tooze, J., S. A. Tooze, and S. D. Fuller. Sorting of progeny coronavirus from condensed secretory proteins at the exit from the trans-Golgi network of AtT20 cells. J. Cell Biol. 105: 12151226, 1987.

37. Zhang, F., D. Crise, B. Su, Y. Hou, J. K. Rose, A. Bothwell, and K. Jacobson. Lateral diffusion of membrane-spanning and glycosylphosphatidylinositol-linked proteins: towards establishing rules governing the lateral mobility of membrane proteins. $J$. Cell Biol. 115: 75-84, 1991.

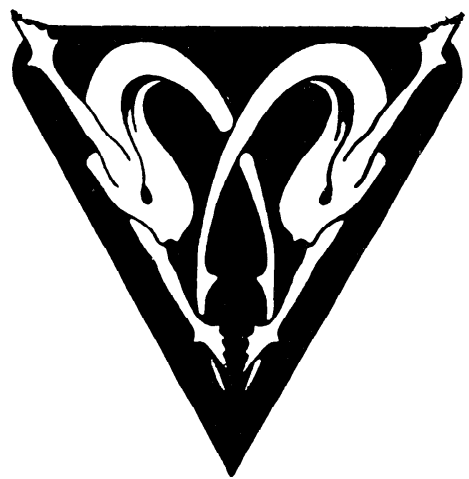

